\title{
Prática profissional e Ética no contexto das políticas de saúde
}

O trabalho, desenvolvido em uma cidade do interior de São Paulo, constitui um estudo das práticas profissionais em saúde e sua dimensão ética, analisadas à luz das políticas liberais e de Bem-Estar Social. Conhecendo as influências dessas políticas nas práticas profissionais e na observância de princípios éticos e de preceitos legais do Sistema único de Saúde, foram entrevistados profissionais da área com responsabilidade de elaboração da política de saúde local, coordenação de instituições de saúde e chefia de unidades ambulatoriais e unidades especializadas. Da leitura das entrevistas identificaram-se quatro núcleos temáticos: Relações entre usuários, serviços e sistema de saúde; relações entre profissionais de saúde $e$ serviços de saúde; relações entre profissionais de saúde e usuários e relações entre profissionais de saúde e o sistema de saúde. A análise das entrevistas apontou desigualdades de acesso aos serviços da rede básica de saúde por falta de estrutura $e$ dificuldades de acesso aos serviços de atenção secundária e terciária, especialmente em algumas áreas, explicadas por uma sobrecarga decorrente das deficiências da rede básica. As dificuldades de acesso aos serviços assistenciais, de acordo com os depoimentos, têm causado o agravamento de doenças pela impossibilidade de se proceder mais precocemente ao diagnóstico $e$ tratamento. O número de internações hospitalares vem diminuindo nos últimos anos. O hospital universitário vem apresentando elevadas taxas de ocupação de leitos devido a uma demanda de doentes cada vez mais graves, ficando impossibilitadas as internações por causas necessárias, porém não urgentes. Em contradição, foi apontada a existência de leitos ociosos do SUS no hospital privado conveniado. Os serviços de saúde do município estão atendendo uma demanda espontânea, de modo desarticulado $e$ descontínuo, precariamente hierarquizado, recaindo sobre os serviços de maior complexidade a responsabilidade compensatória das deficiências de recursos dos demais.

O material revela, também, iniqüidades praticadas por profissionais de saúde na concessão de privilégios quanto ao acesso a serviços diagnósticos, internações ou tempo de espera para atendimento a indivíduos "melhor posicionados socialmente" ou que têm relações de parentesco $e$ amizade.

$O$ estudo permitiu verificar que o referencial bioético da beneficência e não maleficência pode estar comprometido: por uma política social restritiva que faz importantes limitações financeiras para a assistência à saúde; pela necessidade de seleção de pacientes aos benefícios; por critérios inadequados de seleção de pacientes; e pela precariedade das adaptações e improvisações decorrentes da escassez de recursos.

Grande parte dos entrevistados fez referência à gravidade da situação atual do sistema de saúde, apontando as condições adversas enfrentadas no exercício profissional, manifestando uma percepção fatalista do sistema de saúde e uma visão 
mecanicista dos fatos. Como conseqüência, são buscadas saídas alternativas individuais, nem sempre lícitas ou éticas, para a solução dos problemas.

No contexto do sistema capitalista, o confronto entre as duas políticas presentes no setor - a política de bem-estar social, exigindo garantias de direitos sociais, $e$ a política liberal, fazendo restrições $e$, por conseguinte, negando tais direitos - promove ambigüidades $e$ contradições que atingem as dimensões éticas do trabalho profissional na saúde.

Heloisa Wey Berti Mendes Dissertação de Mestrado em Saúde Coletiva, 1999 Faculdade de Medicina de Botucatu, Universidade Estadual Paulista

\title{
Transtornos psiquiátricos e solicitações de interconsulta psiquiátrica em hospital geral:
}

\author{
um estudo caso-controle
}

A interconsulta psiquiátrica (ICP) vem sendo considerada um instrumento de pesquisa, ensino e assistência que traz vantagens $e$ benefícios tanto para o paciente quanto para o profissional de saúde e a instituição. No entanto, a utilização deste recurso no Brasil é ainda pequena. Sabe-se que 30 a $50 \%$ dos pacientes internados em hospital geral (HG) podem apresentar uma patologia psiquiátrica, mas que apenas $1 \%$ a $12 \%$ destes são reconhecidos como tal $e$ encaminhados para avaliação. Pretendeu-se com este trabalho caracterizar os transtornos psiquiátricos em um HG; identificar as diferenças entre pacientes encaminhados e aqueles que não o foram; verificar os motivos de solicitação de ICP $e$ as relações da ICP com o ensino de graduação $e$ residência médica. Para tal realizou-se um estudo caso-controle de 141 pacientes (47 casos e 94 controles), analisando variáveis sócio-demográficas, clínicas, grau de informação quanto à doença, procedimentos diagnósticos e terapêuticos; $e$ relacionamento estabelecido entre pacientes e equipe de saúde. Foram utilizados o Self Report Questionnaire (SRQ), o CAGE e o Brief Psychiatric Rating Scale (BPRS), além de um questionário especialmente elaborado para o estudo. Os critérios diagnósticos utilizados foram da CID-10. Observou-se que alterações de comportamento tanto com manifestações de exaltação (agitação e/ou inquietação) quanto depressivas, aumentaram a freqüência dos pedidos de ICP; $95,8 \%$ dos casos e $27,7 \%$ dos controles receberam um diagnóstico psiquiátrico; transtornos orgânicos e transtornos decorrentes do uso de álcool foram os diagnósticos mais freqüentes no grupo I 